\title{
Da communicação dos bens adqui- ridos no casamento do sexagenario
}

\author{
Francisco Morato
}

\begin{abstract}
1 - Embora de separação forçada o regimen de bens no casamento do sexagenario, communicam-se todavia entre os conjuges os adquiridos na constancia do matrimonio.

2 - Do facto da communhão dos adquiridos pode resultar para o conjuge superstite o direito de continuar, até a partilha pelo inventario do premorto, na posse da herança com o cargo de cabeça de casal.
\end{abstract}

No casamento do sexagenerio não se communicam entre os conjuges os bens existentes ao tempo da celebração das nupcias, por ser necessariamente de separação, por virtude e preceito da lei, o regimen a que estão sujeitos.

Communicam-se, entretanto, os adquiridos na constancia do matrimonio.

E' o principio que está no espirito, no systema, nas tradições antiquissimas e no proprio texto de nossas leis.

Para bem realçar este topico do direito patrio e a genuina intelligencia dos dispositivos do Codigo Civil vem apropositado subir ás fontes e acompanhar, ainda que em breves linhas, a orientação invariavel e diuturna que tem seguido o instituto atravez dos costumes, das licções dos civilistas, do testemunho dos praticos e da doutrina da jurisprudencia.

Adverte e ensina Lobão que a communhão dos adquiridos, na ausencia de pacto expresso em contrario, esteve sempre nos costumes e leis do Reino de Portugal e de outras 
Nações, como attestam e doutrinam Gama, Valasco, Pegas, Weselio, Boetius, Bohmero, Strykio e muitos outros; que nas convenções antenupciaes nunca deixou de ser costume geral resalvar a communicação dos bens adquiridos, conforme demonstram as innumeras escripturas que enchem os cartorios; que em consequencia, sendo omissas as clausulas, é de presumir que os contrahentes se conformaram com este costume (Notas a Mello, L. II, Tit. VIII, § 10).

Foi o thema assaz debatido outr'ora entre os interpretes lusitanos, formando-se em torno delle tres doutrinas divergentes.

Para Mello Freire não se communicavam os bens adquiridos quando o casamento era contrahido com pacto antenupcial de separação ou com dote e arrhas. 0 pacto de separação implicava por si mesmo a incommunicabilidade dos adquiridos, ainda quando a elles se não referisse expressamente. Quando vero conjuges communionem pacto excludunt, vel, nullo pacto adjecto, simpliciter matrimonium contrahunt per dotem et arhas, ab eadem communione tacite recedere videntur; eaque jam locum non habet non solum in bonis qux ipsorum erant tempore matrimonii, verum etiam in adquisitis postea, eo constante (INST. JUR. GIV. LUS. Lib. II, Tit. VIII, § X).

Arrhas diziam-se aquelles bens que no contracto antenupcial com dote o esposo promettia á esposa para depois do casamento, no caso de ella the sobreviver.

Para Coelho da Rocha a simples separação ou exclusão da communhão não importa a incommunicabilidade dos adquiridos. A incommunicabilidade só se dá quando no contracto antenupcial ha declaração expressa nesse sentido ou clausula com ella incompativel, como a de arrhas (DIREITO CIVIL PORTUGUEZ, § 262).

Lobão foi além, sustentando um terceiro ponto de vista, a doutrina verdadeira, que colheu a adhesão da grande torrente dos juristas portuguezes e passou para o direito patrio. Mesmo no casamento com arrhas, ensina o famoso 
jurisconsulto beirão; communicam-se os bens adquiridos; a incommunicabilidade só se verifica quando pactuada expressamente no contracto matrimonial.

Comquanto para nós não tenha consequencias praticas a distincção que fazia Mello Freire e com excelsa maestria impugnava Lobão, de casamento com ou sem arrhas, pois nunca aqui se usou nos casamentos estipular arrhas no sentido antigo, todavia a opinião victoriosa neste dissidio dos lusitanos, dissidio em que Mello Freire e Coelho da Rocha tiveram poucos proselytos, serve de demonstrar que o ponto de vista do direito patrio e da licção geral dos jurisconsultos brasileiros nunca variou e deita longe suas raizes: a communhão dos acquestos é a regra geral, mesmo no regimen dotal ou de separação, regra que só cessa quando excluida por clausula explicita.

Jả em 1858 escrevia Teixeira de Freitas que, quando o casamento é pacticio e não segundo o regimen da communicação legal, sempre se entende que os adquiridos se communicam (ESPINOLA: Questões juridicas e Pareceres, pag. 217).

Não havendo clausula expressa em contrario, escreve Lafayette, communicam-se os adquiridos, assim no regimen da communhão universal como no casamento com pacto de simples separação de bens e no regimen dotal (DIREITOS DE FAMILIA, \&\$ 68 e 82).

Consoante bem illustra João Monteiro, reproduzindo liccão generalizada, cumpre nesta materia seguir o genio do direito patrio e não o do direito romano. No direito romano a presumpção legal é pela separação dos patrimonios dos conjuges, ao passo que pelo nosso, ao contrario, é pela communhão; pelo que si os esposos nada pactuaram sobre os bens futuros, isto é, sobre os adquiridos na constancia do matrimonio, o silencio sobre taes bens não póde deixar de ser havido senão como reflexo da presumpção commum (GAZETA JURIDICA DE S. PAULO, V-11).

Hoje esta doutrina está expressa em texto de Iei. 
Prescreve o Cod. Civil no art. 259 que embora o regimen não seja o da communhão de bens (seja, portanto, de separação ou dotal), prevalecerão, no silencio do contracto, os principios della, quanto á communicação dos adquiridos na constancia do casamento.

Este texto não é mais do que a applicação e desenvolvimento do art. 258 , onde se fixa o principio geral de nosso direito, de que não havendo convenção, vigora entre os conjuges o regimen da communhão universal de bens.

Ao lançar o preceito do art. 259, fal-o o Codigo, alludindo ao silencio do contracto. No regimen de separação pacticia, os adquiridos não se communicam, si houver clausula expressa de incommunicabilidade; no silencio do contracto, communicam-se.

E no regimen de separação resultante da lei, como no casamento do sexagenario? Prevalece o mesmo principio? Entendemos que sim.

Não tocam a questão nem a resolvem os commentadores do Cod. Civil e em geral os que escreveram depois de sua promulgação - verbosi in re facili, in difficili muti.

Os casos de regimen de separação legal obrigatoria, conforme é o do casamento do varão de mais de sessenta annos e da mulher de mais de cincoenta, declina-os o Codigo em paragrapho, como excepção á regra firmada no artigo, de communhão universal em falta de pacto em contrario; como excepção, taes casos têm de ser entendidos restrictamente, envolvendo apenas os bens presentes e não os futuros.

O canone que está nos textos e vem consagrado por uma tradição longeva, segundo acabamos de ver, é que os adquiridos só não se communicam por excepção á regra geral da communhão. Como excepção, para que não se communicassem, necessario seria que a lei assim o determinasse explicitamente.

Quando o legislador, limitando a regra do art. 258, accrescenta em paragrapho uns casos de regimen obrigatorio de separação, é bem de ver que se refere ao regimen normal 
de separação, o qual abarca sómente os bens existentes ao tempo das nupcias e não os futuros. Si fôra seu intento envolver a uns e outros, certo que haveria accrescentado á palavra bens a clausula presentes e futuros.

A excepção aberta por contracto ou aberta por lei, depende sempre de ser expresa.

$\mathrm{O}$ decreto 181 de 24 de Janeiro de 1890, quando attribuiu o caracter de dotaes aos bens, presentes e futuros, da mulher que contrahia nupcias depois dos cincoenta annos, preceito que aliás o Codigo Civil derogou, disse-o de modo expresso e por palavras incisivas - todos os bens da mulher, presentes e futuros.

A incommunicabilidade normal no regimen da separação é sempre a mesma, venha da lei ou venha da convenção.

Seria extranho que na separação pacticia os adquiridos se comunicassem sempre, não dispondo o contrario o contracto, e que na separção obrigatoria nunca se comunicassem, ainda mesmo nada dispondo a lei.

A lei estatue suas regras como expressão dos principios ethicos, dos costumes e da vontade geral presumida. Em boa logica não é licito suppôr traçasse regras contrarias para a mesma relação juridica, segundo é dominada pela convenção das partes ou pela mesma lei.

Ademais, o motivo legal da incommuncabilidade de bens no casamento do sexagenario é o receio e presumpção de que os conjuges sejam attrahidos por sentimentos subalternos de cobiça e especulaçã̃o; motivo que cessa em relação aos adquiridos na constancia do matrimonio e que de maneira alguma os póde attingir - cessante causa legis, cessat lex.

Esta é, pois, a boa doutrina, em face do Codigo Civil, do genio, das tradições e do systema do direito patrio.

Consagrando-a, depara-se um accordam do nosso Tribunal de Justiça, confirmatorio de um julgado de primeira instancia, na Revista dos Tribunaes, vol. 88, pag. 400. 
Da communicação dos adquiridos resultam consequencias de ordem processual.

Si o casal do sexagenario possue bens adquiridos na constancia do matrimonio, de valor superior aos existentes ao tempo das nupcias, e si ao sexagenario sobrevive a muIher ou si á mulher sobrevive o marido, cabe a este ou áquella continuar até a partilha na posse da herança, com o cargo de cabeça de casal ou inventariante.

Cabeça de casal é o conjuge ou herdeiro que está na posse e administração da herança até a partilha. E' o mesmo que inventariante, embora o Codigo Civil reserve o termo mais especialmente para o conjuge superstite, que continúa na posse em que já vinha antes da abertura da successão.

Comquanto o Codigo prescreva no art. 1.579 a regra de que ao conjuge sobrevivente cabe continuar na posse da herança com o cargo de inventariante, no casamento sob o regimen da comunhâo de bens, isto se entende tambem no regimen da separação, relativamente aos bens adquiridos na constancia do matrimonio, porque, quanto a estes, occorre uma perfeita analogia e identidade de motivos, devendo-se, em consequnecia, applicar o mesmo preceito (INTRODUCG.̃̃O AO COD. CIVIL, art. 7).

Como, porém, não se deva admittir, com exercicio simultaneo, dous inventariantes do mesmo espolio e visto que é possivel haver na herança duas categorias de bens - uma dos existentes por occasião das nupcias e incommunicaveis, outra dos adquiridos na constancia do matrimonio e communicaveis; em tal conjunctura cumpre ao juiz do inventario nomear inventariante ao conjuge superstite ou a um dos coherdeiros do premorto, segundo o maior vulto ou valia dos communicaveis ou dos incommunicaveis.

Está bem entendido que tudo que ficou dicto sobre communhão dos acquestos e possivel direito do conjuge superstite á investidura de inventariante, tem logar no regimen forçado de separação por motivo de edade, quer por ser sexagenario o marido, quer por ser quinquagenaria a mulher. 